\title{
HIV testing and burden of HIV infection in black cancer patients in Johannesburg, South Africa: a cross-sectional study
}

Mazvita Sengayi ${ }^{1,2^{*}}$, Chantal Babb ${ }^{1,3}$, Matthias Egger ${ }^{4,5}$ and Margaret I Urban ${ }^{1,3}$

\begin{abstract}
Background: HIV infection is a known risk factor for cancer but little is known about HIV testing patterns and the burden of HIV infection in cancer patients. We did a cross-sectional analysis to identify predictors of prior HIV testing and to quantify the burden of HIV in black cancer patients in Johannesburg, South Africa.

Methods: The Johannesburg Cancer Case-control Study (JCCCS) recruits newly-diagnosed black cancer patients attending public referral hospitals for oncology and radiation therapy in Johannesburg. All adult cancer patients enrolled into the JCCCS from November 2004 to December 2009 and interviewed on previous HIV testing were included in the analysis. Patients were independently tested for HIV-1 using a single ELISA test. The prevalence of prior HIV testing, of HIV infection and of undiagnosed HIV infection was calculated. Multivariate logistic regression models were fitted to identify factors associated with prior HIV testing.

Results: A total of 5436 cancer patients were tested for HIV of whom 1833[33.7\% (95\% Cl=32.5-35.0)] were HIV-positive. Three-quarters of patients (4092 patients) had ever been tested for HIV. The total prevalence of undiagnosed HIV infection was 11.5\% (10.7-12.4) with 34\% (32.0-36.3) of the 1833 patients who tested HIV-positive unaware of their infection. Men >49 years [OR 0.49(0.39-0.63)] and those residing in rural areas [OR 0.61(0.39-0.97)] were less likely to have been previously tested for HIV. Men with at least a secondary education [OR 1.79(1.11-2.90)] and those interviewed in recent years [OR 4.13(2.62 - 6.52)] were likely to have prior testing. Women $>49$ years [OR $0.33(0.27-0.41)$ ] were less likely to have been previously tested for HIV. In women, having children $<5$ years [OR 2.59(2.04-3.29)], hormonal contraceptive use [OR 1.33(1.09-1.62)], having at least a secondary education [OR:2.08(1.45-2.97)] and recent year of interview [OR 6.04(4.45-8.2)] were independently associated with previous HIV testing.
\end{abstract}

Conclusions: In a study of newly diagnosed black cancer patients in Johannesburg, over a third of HIV-positive patients were unaware of their HIV status. In South Africa black cancer patients should be targeted for opt-out HIV testing.

Keywords: HIV testing, Cancer, South Africa

\section{Background}

HIV-1 infection was classified as a human carcinogen by the International Agency for Research on Cancer (IARC) in 1996 [1]. South Africa has the largest HIV burden worldwide with an estimated 6.4 million people living with HIV in mid-2012 [2]. Black Africans are disproportionately

\footnotetext{
*Correspondence: mazvita.sengayi@nhls.ac.za

'NHLS/MRC Cancer Epidemiology Research Group, National Cancer Registry,

National Health Laboratory Service, Johannesburg, South Africa

${ }^{2}$ Graduate School for Cellular and Biomedical Sciences, University of Bern,

Bern, Switzerland

Full list of author information is available at the end of the article
}

affected by the epidemic compared to other population groups. According to the South African 2012 HIV prevalence survey, prevalence in the reproductive age group (15-49 years) was $22.7 \%, 0.6 \%, 4.6 \%$ and $1.0 \%$ in blacks, whites, coloureds (mixed race) and Indians/Asians respectively [2]. In order to understand the burden and spectrum of HIV-related cancers, it is essential to identify people with HIV and cancer co-morbidity. Strategies to identify patients with both HIV infection and cancer include screening for cancers at HIV clinics [3] and testing cancer patients for HIV $[4,5]$. 
The 2010 South African HIV counselling and testing guidelines recommend provider-initiated HIV testing and counselling (PITC) for all patients attending healthcare facilities [6]. PITC is defined as "HIV testing and counselling that is initiated and offered by health-care providers to all clients attending health-care facilities as a standard component of care" [6]. The World Health Organization recommends an 'opt-out' approach to PITC in generalised HIV epidemics (i.e. where antenatal HIV prevalence exceeds 1\%), which not only obliges health care workers to offer HIV testing to every patient, but also incorporates the informed right of the patient to decline the recommendation of an HIV test [7]. In this paper, PITC and opt-out HIV testing will be used synonymously.

PITC has been shown to increase HIV testing almost three-fold in primary care clinics in Gauteng province, South Africa, compared to referral to on-site voluntary counselling and testing services [8]. Challenges to widespread opt-out HIV testing include overburdening a strained healthcare system, ensuring confidentiality in shared consulting rooms, on-going staff training and preventing test kit stock-outs [8]. Therefore there is still a role for targeted PITC among high risk groups, including in antenatal and post-natal clinics, tuberculosis treatment facilities, family planning clinics, sexually transmitted infections clinics and post-exposure prophylaxis centres [6]. Indeed, a recent systematic review of studies in antenatal care concluded that the adoption of PITC can greatly increase testing uptake [9].

HIV testing patterns in the general South African population have been studied: a representative survey in 2005 found that being female, employed, aged 25-34 years, having a higher education and residing in an urban area were all associated with greater knowledge of HIV status [10]. Women have consistently been found to be more likely to know their HIV status than men [2,10-15], even after accounting for pregnancy-related HIV testing [11]. The youth [14], older women [15] and older men $[11,12]$ are less likely to be tested; the majority of older men who test for HIV generally do so when there is a medical indication [11]. Little is known about HIV testing patterns and the burden of HIV infection in cancer patients [4]. The aim of this study was to identify factors associated with HIV testing and to quantify the burden of HIV in newly diagnosed black cancer patients in Johannesburg, Gauteng province, South Africa.

\section{Methods}

\section{Ethics statement}

The study was approved by the University of the Witwatersrand Human Research Ethics Committee (Medical).

\section{Study setting and design}

Since 1995, the Johannesburg Cancer Case-control Study (JCCCS) has recruited newly diagnosed self-defined black cancer patients attending public referral hospitals (Chris Hani Baragwanath, Hillbrow and Charlotte Maxeke Johannesburg Academic Hospital) for oncology and radiation therapy in the greater Johannesburg area [16]. To date, over 20000 black cancer patients have been interviewed, of whom the majority (over 90\%) have donated blood specimens for evaluation of infectious and genetic risk factors for cancer and their interactions with socio-demographic and environmental factors collected via questionnaire. At the time of the current analysis, the JCCCS patient recruitment was confined to only Charlotte Maxeke Johannesburg Academic Hospital (CMJAH) (formerly Johannesburg General Hospital).

\section{Eligibility criteria}

All patients with confirmed cancer, aged $\geq 18$ years, who were enrolled into the JCCCS at CMJAH from November 2004 to December 2009 and who were interviewed on previous HIV testing, were included in this study.

\section{Procedures and definitions}

Trained nurse counsellors used a standard questionnaire to interview cancer patients in their preferred language (usually Zulu or Sotho). All patients gave written or witnessed verbal informed consent prior to being interviewed and having blood drawn. Patients were asked questions on place of birth, rural or urban residence, schooling, reproductive history, use of hormonal contraception, number of lifetime sexual partners, and alcohol and tobacco use. From November 2004, in addition to the standard questionnaire, all patients aged 55 or less were asked about previous HIV testing. After November 2006, all recruited patients were interviewed on prior HIV testing. Patients were asked the following questions to explore their HIV testing patterns: Have you ever been tested for HIV? Were you tested: before this illness/ at time of current illness only? Were you given the test results? Are you willing to disclose your status? If yes, are you HIV positive or negative?

Nurse counsellors took blood samples from consenting patients at the time of interview, before patients had received any cancer treatment. Blood samples were collected in $10 \mathrm{ml}$ red-top plain vacutainers. Serum separation was done by standard centrifugation, and serum specimens were frozen at -20 to $-30^{\circ} \mathrm{C}$ before batching for HIV testing. Specimens were tested for HIV-1 using a single Vironostika (HIV Uniform II plus O) micro enzyme-linked immunosorbent assay (ELISA) test. Specimens with inconclusive ELISA tests were classified as HIV negative. All tests were done at the Serology Laboratory, 
Centre for HIV and STIs, National Institute for Communicable Diseases, Johannesburg.

Prior HIV testing was defined as self-reported history of HIV testing before the current cancer illness. Awareness of HIV status was defined as self-reported HIV status consistent with the result of the HIV-1 ELISA test. Cancers were classified according to the International Classification of Diseases for Oncology Third Edition (ICD-O-3) [17]. We classified cervical cancer (ICD-O topography code C53), Kaposi sarcoma (ICD-O morphology code M91403) and non-Hodgkin lymphoma (ICDO topography codes C82-83 or ICD-O morphology code M9590 - 9595, M9670 - 9717 and M9820 - 9837) as AIDS-defining cancers [18]. The majority (98.4\%) of patients included in the analysis had verification of cancer diagnosis by histology, haematology or cytology. Coding of cancers was done by an experienced coder working for the JCCCS and quality controlled by one of the authors (MIU) who has extensive coding expertise; assistance from oncologists, histopathologists and/or cytologists was sought where needed.

\section{Statistical analyses}

We used means and proportions to describe the characteristics of newly diagnosed cancer patients. We determined the ten most frequent cancers in men and in women by HIV status and calculated the prevalence of prior HIV testing, of HIV infection and of undiagnosed HIV, with exact binomial 95\% confidence intervals (CI). We compared age-specific HIV prevalence in male and female black cancer patients with HIV prevalence in black men and women in the South African general population, as reported in the 2008 national HIV prevalence survey [19]. We also calculated prevalence of HIV and undiagnosed HIV by cancer type (see Additional file 1 : Table S6).

We fitted logistic regression models to identify factors associated with prior HIV testing in black cancer patients. Separate models were calculated for men and women. The following variables were entered into the models: age ( $\leq 49$ years, $>49$ years), place of residence (rural vs. urban), marital status (married, single, widowed, divorced), year of interview, highest level of education achieved (none, primary and secondary/tertiary), alcohol use (non-drinkers, moderate drinkers and heavy/binge drinkers), smoking (non-smokers, ex-smokers, current light smokers and current heavy smokers), lifetime number of sexual partners $(0-1,2-5$ and 6 or more), having children under the age of five, cancer type (AIDS defining or other cancers), hormonal contraceptive use (ever, never) and interviewer. We had three nurse interviewers: interviewer 1 , the most senior interviewer, was with the study during the entire period; interviewer 3 replaced interviewer 2 in September 2009. We classified alcohol use as follows: non-drinkers
( $<1$ drink per week), moderate drinkers (1-7 drinks/week for women, 1-14 drinks/week for men) and heavy/binge drinkers (8 or more drinks/week or 4 or more drinks in a single occasion for women, 15 or more drinks/week or 5 or more drinks in a single occasion for men) [20]. We considered that some patients may have quit smoking due to their illness; hence those who stopped smoking more than 5 years prior to the date of interview were classified as ex-smokers while those who smoked within 5 years of the date of interview were classified as current smokers. Current smokers were further classified into 'light' (1 $14 \mathrm{~g} /$ day) and 'heavy' ( $15 \mathrm{~g} /$ day or more) current smokers, assuming weights of $1 \mathrm{~g}$ per cigarette or hand rolled cigarette or pipe [21].

We added variables to multivariate models sequentially, starting with variables with the smallest $p$ value in univariate analysis. Likelihood ratio tests were performed to determine which variables were kept in the models. The final model for men was adjusted for age, place of residence, highest level of education achieved, year of interview and interviewer. The final model for women was adjusted for age, highest level of education achieved, year of interview, having children under the age of five, hormonal contraceptive use and interviewer. Stata software (version 13, Stata Corporation, College Station, Texas, USA) was used for all analyses.

\section{Results}

\section{Characteristics of cancer patients}

Out of the 7012 eligible patients who were approached, 270 did not participate, 1300 were not interviewed on HIV testing and 69 did not have HIV screening test results (Figure 1). Reasons for non-participation were: too sick/in pain 105 (39\%), unable to communicate 56 (21\%), refused 44 (16\%), left before interview 33 (12\%), impaired cognitive function $28(10 \%)$ and other $4(2 \%)$. The remaining study sample had 5436 patients with HIV test results. Two thirds of patients were female and 54\% patients were 49 years old or younger (Table 1). The majority $(89 \%)$ were urban dwellers and 58\% were married or lived with their partner. Forty percent of patients had completed primary education or less. Fifteen percent were heavy/binge alcohol drinkers and $28 \%$ were current smokers. A quarter of all patients had had more than five sexual partners in their lifetime. Only 13\% had children under the age of five. The majority of women (63\%) had previously used hormonal contraceptives. Missing data were $\leq 2 \%$ for all variables, except for the variable "having children under 5 years", where $9.3 \%$ of data were missing.

\section{Cancers in men and women by HIV status}

The five most common cancers in HIV-positive men were Kaposi sarcoma (KS), non-Hodgkin lymphoma (NHL), 


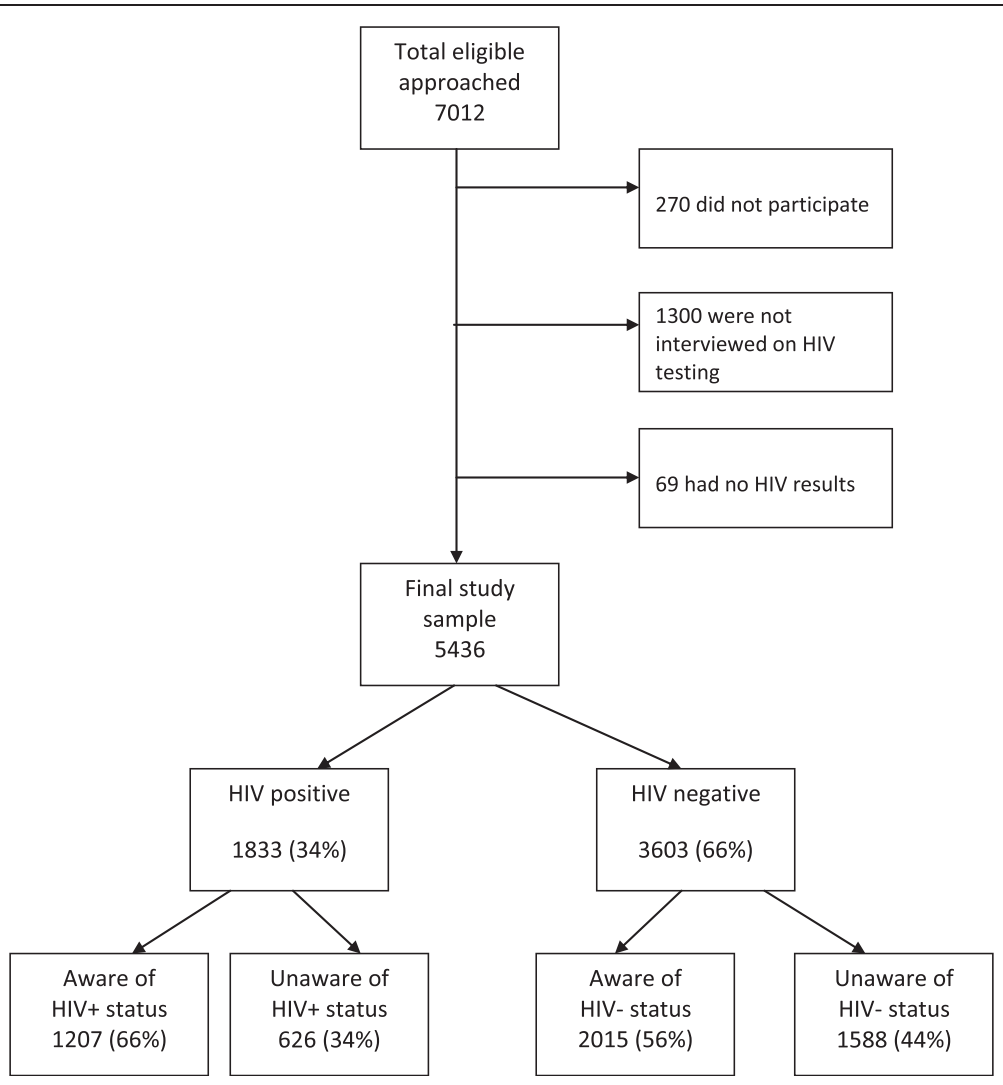

Figure 1 Flowchart of cancer patient recruitment (2004 - 2009).

oro-pharyngeal, lung and naso-laryngeal cancers, totalling $75 \%$ of all cancers (Table 2). In HIV-negative men, the top five cancers were oro-pharyngeal, lung, oesophageal, naso-laryngeal and stomach cancers, totalling $54 \%$ of all cancers. For HIV-positive women, the five most common cancers were cervical, breast, KS, NHL and oro-pharyngeal cancer, totalling $84 \%$ of all cancers. In HIV-negative women, the top five cancers were breast, cervical, oesophageal, ovarian and uterine cancer, totalling $77 \%$ of all cancers.

\section{HIV testing and prevalence in cancer patients}

Among patients with available results, 1833 had a positive ELISA test, for a prevalence of HIV infection of $33.7 \%$ (95\% CI 32.5-35.0). Out of the 1833 cancer patients with a positive HIV-1 test, 626 [34\% (95\% CI 32.0 - 36.3)] were unaware of their positive HIV status. The overall prevalence of previously undiagnosed HIV among all black cancer patients was 11.5\% (95\% CI 10.7-12.4): 626 patients out of 5436 patients with HIV test results. Among the 3603 patients who tested HIV-1 negative, 1588 (44\%) were unaware of their HIV status.

Figure 2 and Figure 3 compare the age-specific HIV prevalence in black men and women with cancer to black men and women in the general South African population [19]. In men with KS or NHL age-specific HIV prevalence was high ranging from $96.3 \%$ to $100 \%$ for $\mathrm{KS}$ and $33.3 \%$ to $100 \%$ for NHL, in the age groups 20 to 60 years. In men with other cancers HIV prevalence was generally slightly higher in black cancer patients than in the black male population. HIV prevalence in black men with other cancers rose with age, peaking in the 35-39 years age group and then declining to below $10 \%$ in men 60 years or older. In women the pattern was similar to that observed in men for KS, NHL and for other cancers. The pattern differed for cervical cancer: HIV prevalence was $100 \%$ in women aged $20-24$ years and steadily declined with increasing age to $10 \%$ in women aged 60 or older (Figure 3).

\section{Factors associated with prior HIV testing}

A total of 4092 (75\%) out of 5436 patients had ever been tested for HIV; of those, 1303 (32\%) had been tested before their current cancer illness. The remaining 2789 (68\%) had been tested for HIV at the time of their cancer illness or diagnosis. The median time elapsed since the last HIV test at time of interview was 1.9 months (IQR 1.0 - 5.6). Only $19(<1 \%)$ out of the 4092, who had ever been tested, were unwilling to disclose the results of their previous HIV test. Factors independently associated 
Table 1 Characteristics of newly diagnosed black South African cancer patients (2004 - 2009)

\begin{tabular}{|c|c|c|}
\hline Characteristics & $\mathrm{N}$ & $\%$ \\
\hline \multicolumn{3}{|l|}{ Age } \\
\hline$\leq 49$ years & 2954 & 54.3 \\
\hline$>49$ years & 2482 & 45.7 \\
\hline Mean (Standard deviation) & $47.8(12.2)$ & \\
\hline \multicolumn{3}{|l|}{ Place of residence } \\
\hline Urban & 4840 & 89.0 \\
\hline Rural & 591 & 10.9 \\
\hline Missing data & 5 & 0.1 \\
\hline \multicolumn{3}{|l|}{ Gender } \\
\hline Male & 1793 & 33.0 \\
\hline Female & 3643 & 67.0 \\
\hline \multicolumn{3}{|l|}{ Marital status } \\
\hline Married/Living together & 3147 & 57.9 \\
\hline Single/Never married & 680 & 12.5 \\
\hline Widowed & 737 & 13.6 \\
\hline Separated/Divorced & 863 & 15.9 \\
\hline Missing data & 9 & 0.2 \\
\hline \multicolumn{3}{|l|}{ HIV Screening test result } \\
\hline Negative & 3603 & 66.3 \\
\hline Positive & 1833 & 33.7 \\
\hline \multicolumn{3}{|l|}{ Level of education } \\
\hline None & 549 & 10.1 \\
\hline Primary & 1641 & 30.2 \\
\hline Secondary/Tertiary & 3238 & 59.6 \\
\hline Missing data & 8 & 0.2 \\
\hline \multicolumn{3}{|l|}{ Alcohol use } \\
\hline Non-drinkers & 3253 & 59.8 \\
\hline Moderate drinkers & 1342 & 24.7 \\
\hline Heavy/Binge drinkers & 841 & 15.5 \\
\hline \multicolumn{3}{|l|}{ Smoking } \\
\hline Non-smokers & 3436 & 63.2 \\
\hline Ex-smokers & 457 & 8.4 \\
\hline Current smokers ( 1 - 14 g/day) & 1099 & 20.2 \\
\hline Current smokers (15+ g/day) & 444 & 8.2 \\
\hline \multicolumn{3}{|c|}{ Lifetime number of sexual partners } \\
\hline $0-1$ & 585 & 10.8 \\
\hline $2-5$ & 3401 & 62.6 \\
\hline $6+$ & 1343 & 24.7 \\
\hline Missing data & 107 & 2.0 \\
\hline \multicolumn{3}{|l|}{ Having children under 5 years } \\
\hline No & 4233 & 77.9 \\
\hline Yes & 700 & 12.9 \\
\hline Missing data & 503 & 9.3 \\
\hline
\end{tabular}

Table 1 Characteristics of newly diagnosed black South African cancer patients (2004 - 2009) (Continued)

\begin{tabular}{lll}
\hline Cancer type & & \\
AIDS-defining & 1923 & 35.4 \\
Other cancers & 3513 & 64.6 \\
Hormonal contraceptive use (Women only) & & \\
Never & 1329 & 36.5 \\
Ever & 2299 & 63.1 \\
Missing data & 15 & 0.4 \\
Interviewer & & \\
Interviewer 1 & 3161 & 58.2 \\
Interviewer 2 & 2074 & 38.1 \\
Interviewer 3 & 201 & 3.7 \\
\hline
\end{tabular}

with prior HIV testing in men included younger age, urban residence, higher level of education and more recent year of interview (Table 3). For example, men with secondary/tertiary education had a 1.79 times greater odds of a prior HIV test than men with no education. Similarly, in women, younger age, higher level of education and more recent year of interview were associated with prior testing. In addition, having children under the age of five and hormonal contraceptive use were independently associated with prior HIV testing (Table 4).

\section{Discussion}

The prevalence of HIV infection in black cancer patients diagnosed in a large tertiary academic hospital in Johannesburg, South Africa was 34\%, demonstrating a higher HIV prevalence in black cancer patients than in the general black population. While three-quarters of all patients had ever been tested for HIV, about a third of the infected patients were unaware of their HIV infection. Overall more than $10 \%$ of all newly diagnosed black cancer patients had a previously unknown HIV infection. The HIV prevalence in this population was substantially higher than the national South African adult HIV prevalence of $18 \%$ [19] but comparable with other high risk groups. For example, the National Antenatal Sentinel HIV and Syphilis Prevalence survey showed that $29 \%$ of pregnant women were HIV positive in 2009 [22]. HIV prevalence in cancer patients is expected to be high since HIV is a wellestablished risk factor for AIDS-defining cancers, but the prevalence was also higher in patients with cancers that are not classified as AIDS-defining. Overall HIV prevalence in cancer patients in a previous JCCCS publication covering the period March 1995 - June 2004, was found to be $10 \%$ [16]. The current analysis, covering the period November 2004 - December 2009 found a much higher prevalence of $34 \%$. The difference in the HIV seropositivity reflects the different stages of the South African HIV epidemic in the two time periods. The much lower 
Table 2 Ten most frequent cancers in black South African men and women by HIV status (2004 - 2009)

\begin{tabular}{|c|c|c|c|}
\hline \multicolumn{2}{|l|}{ HIV positive men $(n=596)$} & \multicolumn{2}{|l|}{ HIV negative men $(n=1197)$} \\
\hline Kaposi sarcoma & $260(43.6)$ & Lip, oral cavity and pharynx & $216(18.1)$ \\
\hline $\mathrm{NHL}$ & $94(15.8)$ & Lung & $167(14.0)$ \\
\hline Diffuse large B cell lymphoma & $54(9.1)$ & & \\
\hline Burkitt's lymphoma & $6(1.0)$ & & \\
\hline Other NHL & $34(5.7)$ & & \\
\hline Lip, oral cavity and pharynx & $38(6.4)$ & Oesophagus & $125(10.4)$ \\
\hline Lung & $34(5.7)$ & Nasal cavity and larynx & $82(6.9)$ \\
\hline Nasal cavity and larynx & $21(3.5)$ & Stomach & $54(4.5)$ \\
\hline Oesophagus & $19(3.2)$ & Colon & $45(3.8)$ \\
\hline Hodgkin Lymphoma & $15(2.5)$ & Anorectal & $45(3.8)$ \\
\hline Liver & $11(1.9)$ & Liver & $45(3.8)$ \\
\hline Stomach & $9(1.5)$ & Pancreas & $39(3.3)$ \\
\hline Skin (non-melanoma, non-SCC*) & $7(1.2)$ & Prostate & $39(3.3)$ \\
\hline HIV positive women $(n=1237)$ & & HIV negative women $(n=2406)$ & \\
\hline Cervix & $448(36.2)$ & Breast & $874(36.3)$ \\
\hline Breast & $241(19.5)$ & Cervix & $718(29.8)$ \\
\hline Kaposi sarcoma & $226(18.3)$ & Oesophagus & $93(3.9)$ \\
\hline $\mathrm{NHL}$ & $95(7.7)$ & Ovary & $89(3.7)$ \\
\hline Diffuse large B cell lymphoma & $61(4.9)$ & & \\
\hline Burkitt's lymphoma & $9(0.7)$ & & \\
\hline Other NHL & $25(2.0)$ & & \\
\hline Lip, oral cavity and pharynx & $26(2.1)$ & Uterus & $84(3.5)$ \\
\hline Vulva & $22(1.8)$ & Colon & $54(2.2)$ \\
\hline Uterus & $17(1.4)$ & Lip, oral cavity and pharynx & $51(2.1)$ \\
\hline Conjunctiva, Eye & $17(1.4)$ & Lung & $48(2.0)$ \\
\hline Lung & $15(1.2)$ & Anorectal & $39(1.6)$ \\
\hline \multirow[t]{4}{*}{ Oesophagus } & $14(1.1)$ & $\mathrm{NHL}$ & $30(1.3)$ \\
\hline & & Diffuse large B cell lymphoma & $10(0.4)$ \\
\hline & & Burkitt's lymphoma & $2(0.1)$ \\
\hline & & Other NHL & $18(0.8)$ \\
\hline
\end{tabular}

Numbers (\%) are shown.

*non-squamous cell carcinoma.

HIV prevalence in 1990s might have affected overall HIV prevalence in previous JCCCS publications exemplified by an antenatal HIV prevalence of $10.4 \%$ in 1995 which steadily rose to $29.5 \%$ in 2004 , plateauing around this level in the years 2004 to 2012 [23].

We found that younger age, higher level of education and more recent year of interview were associated with having been tested for HIV both in men and in women. Older men and women were less likely to have been tested; this is consistent with a study of age and gender differences in HIV testing uptake done in South Africa's Mpumalanga province [11]. In Mpumalanga the peak age-group for HIV testing was 20-39 years for both men and women; older men and women were less likely to get tested and a significant proportion of older people who did test did so only after medical referral [11]. Black cancer patients interviewed in more recent years had a higher odds of prior HIV testing and, similarly, there was an increase in HIV testing in the Mpumalanga study from 2002 to 2006 [11]. Greater availability of HIV testing facilities and of antiretroviral treatment could partially explain improved testing coverage in recent years. As expected, higher level of education was associated with greater prevalence of prior HIV testing in both men and women [14,24]. Indeed, the determinants of HIV testing in black men and women with cancer are similar to those seen in the general South African population $[10,11,14,15]$. 


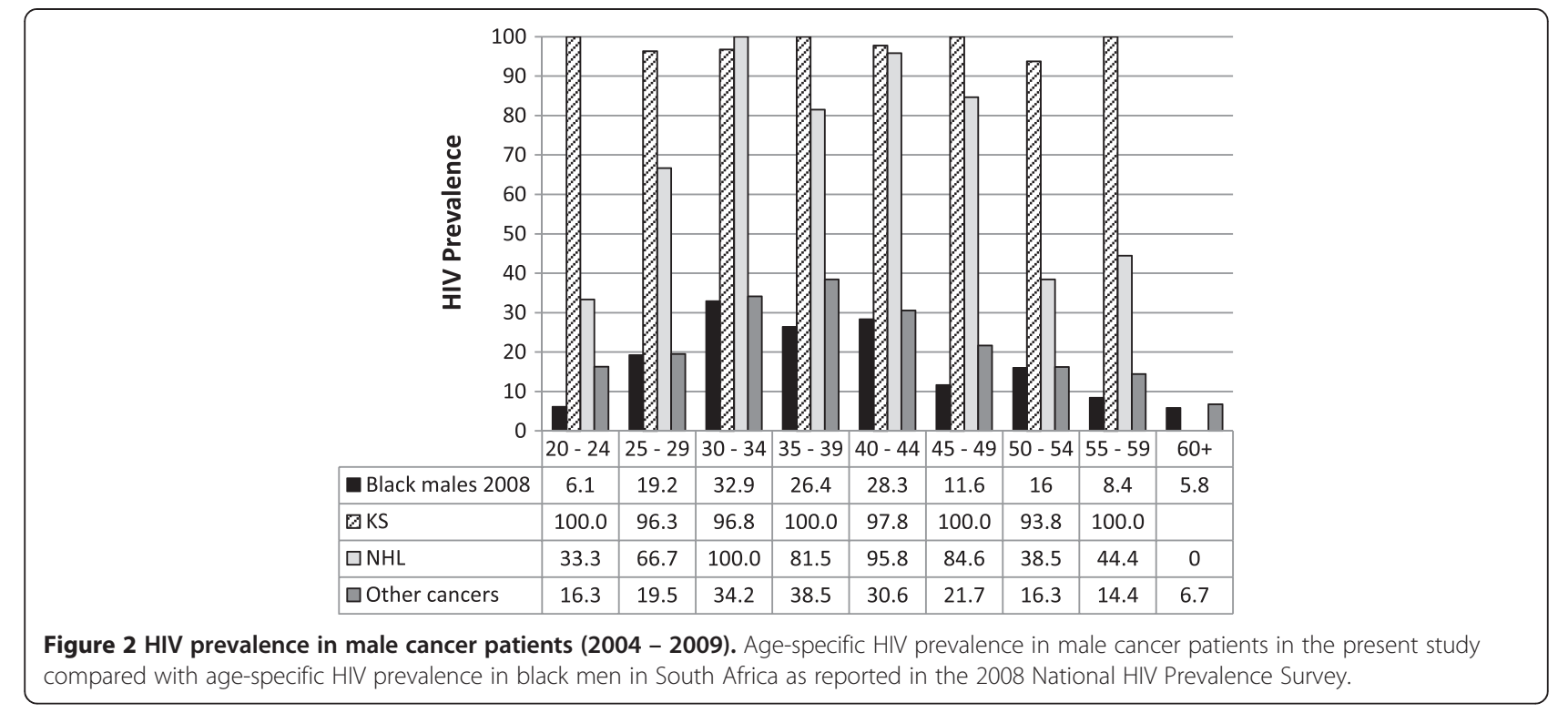

Women having children under the age of five or using hormonal contraceptives were also more likely to have been tested for HIV. Younger women who use hormonal contraception and who have small children would have attended health facilities where they will have been offered HIV testing [15]. Routine opt-out antenatal HIV testing in pregnant women has been part of the prevention of mother-to-child transmission of HIV (PMTCT) programme since 2001 [25], which probably explains the higher HIV testing prevalence in women with young children. This finding underscores the potential of implementation of PITC when patients with cancer and HIV co-morbidity can be identified thereby allowing for appropriate treatment and referral for HIV care.

Men and women with KS had a persistently high HIV prevalence across the age-groups, whereas for cervical cancer the prevalence was highest in young women and declined steadily with increasing age. This is consistent with the young age at cervical cancer diagnosis as previously described in HIV positive women in South Africa [26], and supports the hypothesis that HIV works as a cofactor which shortens the pre-invasive stage in cervical carcinogenesis [26]. The leading cancers in men and women differed by HIV status, with AIDS-defining cancers accounting for $59 \%$ and $62 \%$ of all cancers in HIV positive men and women respectively. The nonAIDS defining cancers Hodgkin lymphoma and skin (non-melanoma, non-squamous cell carcinoma) in men, and vulval and conjunctival cancers in women emerged in the top ten. The association of these nonAIDS defining cancers with HIV has been described before in the JCCCS [16] and in other African settings

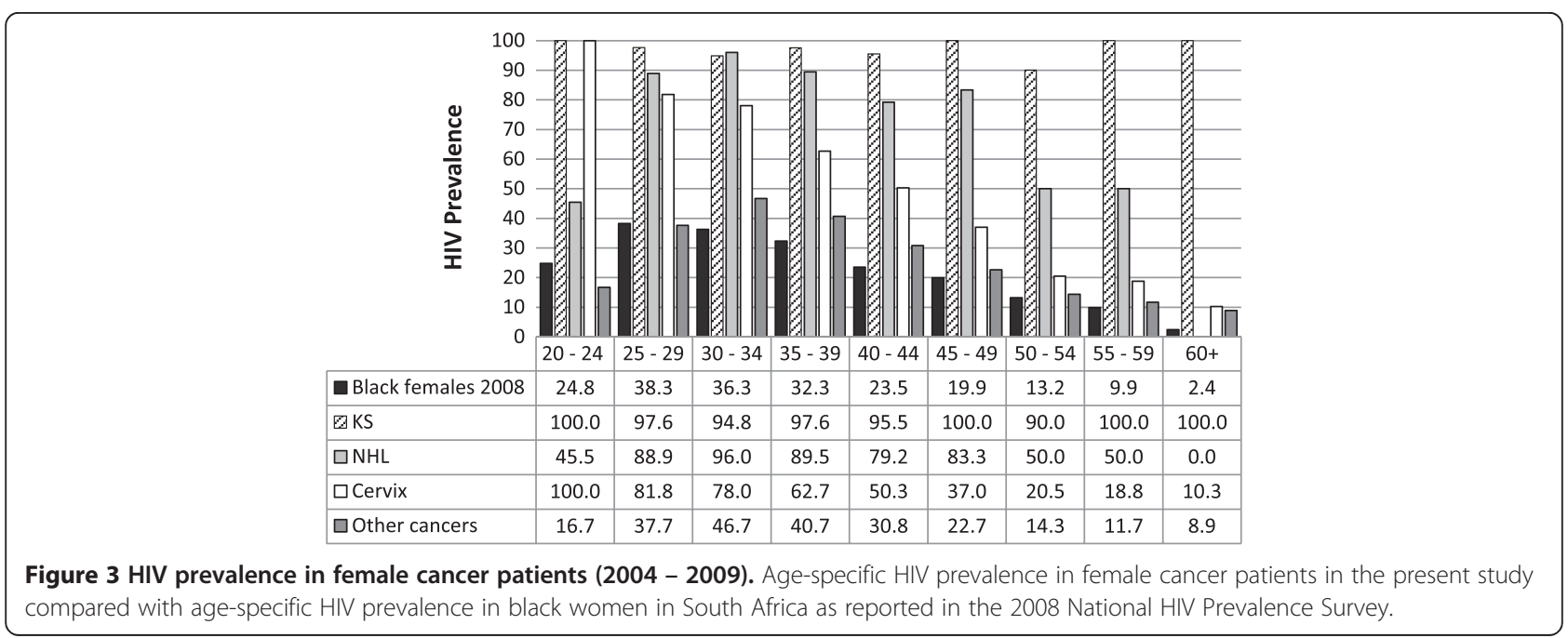


Table 3 Factors associated with HIV testing in black South African men with cancer (2004 - 2009)

\begin{tabular}{|c|c|c|c|c|}
\hline Factor & $\begin{array}{l}\text { No previous HIV test } \\
\mathrm{N}(\%)\end{array}$ & $\begin{array}{l}\text { Previous HIV test } \\
\mathrm{N}(\%)\end{array}$ & $\begin{array}{l}\text { Crude logistic model } \\
\text { OR }(95 \% \mathrm{Cl})\end{array}$ & $\begin{array}{l}\text { Multivariate logistic model } \\
\text { OR }(95 \% \mathrm{Cl})\end{array}$ \\
\hline \multicolumn{5}{|l|}{ Age } \\
\hline$\leq 49$ years & $641(45.8)$ & $238(60.7)$ & 1 & 1 \\
\hline$>49$ years & $760(54.2)$ & $154(39.3)$ & $0.54(0.43-0.68)$ & $0.49(0.39-0.63)$ \\
\hline \multicolumn{5}{|l|}{ Place of residence } \\
\hline Urban & $1241(88.6)$ & $367(93.6)$ & 1 & 1 \\
\hline Rural & $160(11.4)$ & $25(6.4)$ & $0.53(0.34-0.82)$ & $0.61(0.39-0.97)$ \\
\hline \multicolumn{5}{|l|}{ Marital status } \\
\hline Married/living together & $960(68.6)$ & $249(63.7)$ & 1 & \\
\hline Single/never married & $170(12.2)$ & $48(12.3)$ & $1.09(0.77-1.54)$ & \\
\hline Widowed & $99(7.1)$ & $36(9.2)$ & $1.40(0.93-2.10)$ & \\
\hline Separated/divorced & $170(12.2)$ & $58(14.8)$ & $1.32(0.95-1.83)$ & \\
\hline \multicolumn{5}{|l|}{ Year of interview } \\
\hline 2004-2005 & $197(14.1)$ & $30(7.7)$ & 1 & 1 \\
\hline 2006 & $235(16.8)$ & $38(9.7)$ & $1.06(0.63-1.78)$ & $1.04(0.61-1.76)$ \\
\hline 2007 & $351(25.1)$ & 77 (19.6) & $1.44(0.91-2.27)$ & $1.88(1.17-3.02)$ \\
\hline 2008 & $355(25.3)$ & $107(27.3)$ & $1.98(1.27-3.07)$ & $2.44(1.54-3.85)$ \\
\hline 2009 & $263(18.8)$ & $140(35.7)$ & $3.49(2.26-5.40)$ & $4.13(2.62-6.52)$ \\
\hline \multicolumn{5}{|l|}{ Level of education } \\
\hline None & $145(10.4)$ & $24(6.1)$ & 1 & 1 \\
\hline Primary & $495(35.4)$ & $94(24.0)$ & $1.15(0.71-1.86)$ & $1.14(0.69-1.89)$ \\
\hline Secondary/tertiary & $758(54.2)$ & $274(69.9)$ & $2.18(1.39-3.44)$ & $1.79(1.11-2.90)$ \\
\hline \multicolumn{5}{|l|}{ Alcohol use } \\
\hline Non-drinkers & $397(28.3)$ & $118(30.1)$ & 1 & \\
\hline Moderate drinkers & $635(45.3)$ & $165(42.1)$ & $0.87(0.67-1.14)$ & \\
\hline Heavy/binge drinkers & $369(26.3)$ & $109(27.8)$ & $0.99(0.74-1.34)$ & \\
\hline \multicolumn{5}{|l|}{ Smoking } \\
\hline Non-smokers & $318(22.7)$ & $100(25.5)$ & 1 & \\
\hline Ex-smokers & $221(15.8)$ & $52(13.3)$ & $0.75(0.51-1.09)$ & \\
\hline Current smokers (1-14 g/day) & $580(41.4)$ & $155(39.5)$ & $0.85(0.64-1.13)$ & \\
\hline Current smokers (15+ g/day) & $282(20.1)$ & $85(21.7)$ & $0.96(0.69-1.33)$ & \\
\hline \multicolumn{5}{|c|}{ Lifetime number of sexual partners } \\
\hline $0-1$ & $89(6.5)$ & $21(5.5)$ & 1 & \\
\hline $2-5$ & $633(46.3)$ & $156(41.2)$ & $1.04(0.63-1.73)$ & \\
\hline $6+$ & $645(47.2)$ & $202(53.3)$ & $1.33(0.80-2.19)$ & \\
\hline \multicolumn{5}{|l|}{ Having children under 5 years } \\
\hline No & $828(79.8)$ & $228(75.2)$ & 1 & \\
\hline Yes & $210(20.2)$ & $75(24.8)$ & $1.30(0.96-1.75)$ & \\
\hline \multicolumn{5}{|l|}{ Cancer type } \\
\hline AIDS-defining & $294(21.0)$ & $104(26.5)$ & 1 & \\
\hline Other cancers & $1107(79.0)$ & $288(73.5)$ & $0.73(0.57-0.95)$ & \\
\hline \multicolumn{5}{|l|}{ Interviewer } \\
\hline Interviewer 1 & $771(55.0)$ & $291(74.2)$ & 1 & 1 \\
\hline Interviewers 2 and 3 & $630(45.0)$ & $101(25.8)$ & $0.69(0.63-0.76)$ & $0.43(0.33-0.56)$ \\
\hline
\end{tabular}


Table 4 Factors associated with HIV testing in black South African women with cancer

\begin{tabular}{|c|c|c|c|c|}
\hline Factor & $\begin{array}{l}\text { No previous HIV test } \\
\mathrm{N}(\%)\end{array}$ & $\begin{array}{l}\text { Previous HIV test } \\
\mathrm{N}(\%)\end{array}$ & $\begin{array}{l}\text { Crude logistic model } \\
\text { OR }(95 \% \mathrm{Cl})\end{array}$ & $\begin{array}{l}\text { Multivariate logistic model } \\
\text { OR }(95 \% \mathrm{Cl})\end{array}$ \\
\hline \multicolumn{5}{|l|}{ Age } \\
\hline$\leq 49$ years & $1368(50.1)$ & 707 (77.6) & 1 & 1 \\
\hline$>49$ years & $1364(49.9)$ & $204(22.4)$ & $0.29(0.24-0.34)$ & $0.33(0.27-0.41)$ \\
\hline \multicolumn{5}{|l|}{ Place of residence } \\
\hline Urban & $2392(87.7)$ & $840(92.3)$ & 1 & \\
\hline Rural & $336(12.3)$ & $70(7.7)$ & $0.59(0.45-0.78)$ & \\
\hline \multicolumn{5}{|l|}{ Marital status } \\
\hline Married/living together & $1503(55.1)$ & $435(47.9)$ & 1 & \\
\hline Single/never married & $280(10.3)$ & $182(20.0)$ & $2.24(1.81-2.78)$ & \\
\hline Widowed & $483(17.7)$ & $119(13.1)$ & $0.85(0.68-1.07)$ & \\
\hline Separated/divorced & $462(16.9)$ & $173(19.0)$ & $1.29(1.05-1.59)$ & \\
\hline \multicolumn{5}{|l|}{ Year of interview } \\
\hline $2004-2005$ & $497(18.2)$ & $77(8.5)$ & 1 & 1 \\
\hline 2006 & $433(15.8)$ & $99(10.9)$ & $1.47(1.07-2.04)$ & $1.61(1.14-2.28)$ \\
\hline 2007 & $642(23.5)$ & $173(19.0)$ & $1.74(1.30-2.33)$ & $2.91(2.10-4.01)$ \\
\hline 2008 & $648(23.7)$ & $231(25.4)$ & $2.30(1.73-3.05)$ & $3.62(2.65-4.95)$ \\
\hline 2009 & $512(18.7)$ & $331(36.3)$ & $4.17(3.16-5.50)$ & $6.04(4.45-8.21)$ \\
\hline \multicolumn{5}{|l|}{ Level of education } \\
\hline None & $336(12.3)$ & $44(4.8)$ & 1 & 1 \\
\hline Primary & $880(32.3)$ & $172(18.9)$ & $1.49(1.04-2.13)$ & $1.26(0.86-1.84)$ \\
\hline Secondary/tertiary & $1511(55.4)$ & $695(76.3)$ & $3.51(2.53-4.87)$ & $2.08(1.45-2.97)$ \\
\hline \multicolumn{5}{|l|}{ Alcohol use } \\
\hline Non-drinkers & $2071(75.8)$ & $667(73.2)$ & 1 & \\
\hline Moderate drinkers & $401(14.7)$ & $141(15.5)$ & $1.09(0.88-1.35)$ & \\
\hline Heavy/binge drinkers & $260(9.5)$ & $103(11.3)$ & $1.23(0.96-1.57)$ & \\
\hline \multicolumn{5}{|l|}{ Smoking } \\
\hline Non-smokers & $2240(82.0)$ & $778(85.4)$ & 1 & \\
\hline Ex-smokers & $152(5.6)$ & $32(3.5)$ & $0.61(0.41-1.90)$ & \\
\hline Current smokers (1-14 g/day) & $278(10.2)$ & $86(9.4)$ & $0.89(0.69-1.15)$ & \\
\hline Current smokers (15+ g/day) & $62(2.3)$ & $15(1.6)$ & $0.70(0.39-1.23)$ & \\
\hline \multicolumn{5}{|c|}{ Lifetime number of sexual partners } \\
\hline $0-1$ & $383(14.3)$ & $92(10.3)$ & $1.38(1.08-1.76)$ & \\
\hline $2-5$ & $1962(73.0)$ & $650(72.5)$ & $1.87(1.39-2.52)$ & \\
\hline $6+$ & $342(12.7)$ & $154(17.2)$ & & \\
\hline Having children under 5 years & & & 1 & 1 \\
\hline No & $2497(92.8)$ & $680(75.5)$ & $4.18(3.39-5.16)$ & $2.59(2.04-3.29)$ \\
\hline Yes & $194(7.2)$ & $221(24.5)$ & & \\
\hline \multicolumn{5}{|l|}{ Cancer type } \\
\hline AIDS-defining & $1140(41.7)$ & $385(42.3)$ & 1 & \\
\hline Other & $1592(58.3)$ & $526(57.7)$ & $0.98(0.84-1.14)$ & \\
\hline \multicolumn{5}{|l|}{ Hormonal contraceptive use } \\
\hline Never & $1105(40.6)$ & $224(24.7)$ & 1 & 1 \\
\hline Ever & $1615(59.4)$ & $684(75.3)$ & $2.09(1.76-2.47)$ & $1.33(1.09-1.62)$ \\
\hline
\end{tabular}


Table 4 Factors associated with HIV testing in black South African women with cancer (Continued)

\begin{tabular}{|c|c|c|c|c|}
\hline \\
\hline \multicolumn{5}{|l|}{$\begin{array}{l}\text { Interviewer } \\
\text { Interviewer } 1\end{array}$} \\
\hline Interviewers 2 and 3 & $1306(47.8)$ & $238(26.1)$ & $0.74(0.69-0.78)$ & $0.36(0.30-0.44)$ \\
\hline
\end{tabular}

[27-30]. Anal cancer is the most common non-AIDS defining cancer in HIV positive men in Europe and the United States [31]. The conspicuous absence of anorectal cancers in the top ten cancers in HIV positive black men in our study can be explained by the predominantly heterosexual transmission of HIV in South Africa [32]. Conjunctival cancer was detected among the top ten cancers in HIV positive female black cancer patients but was not in the top ten cancers in HIV positive men. This might reflect differences in health seeking behaviours between men and women, hindering diagnosis in men. Also, it might possibly reflect an HIV-related shift from the male predominance of conjunctival cancer to a female predominance as previously observed in a study of conjunctival cancer in Zimbabwe, where $70 \%$ of conjunctival cancers were in women [33].

The overall undiagnosed HIV prevalence of $11.5 \%$ is comparable to other studies done in the general population; the prevalence of previously undiagnosed HIV was $10.3 \%$ in a population-based sero-survey done in Cape Town [13]. In the current study, over a third of HIV positive cancer patients were unaware of their HIV status. This is concerning and has implications for management of cancer patients. Undiagnosed HIV infection could potentially worsen treatment outcomes for cancer patients, who might have untreated HIV-related immunodeficiency in addition to coping with cancer-specific chemotherapy, radiation therapy or surgery. Further research is required to understand why newly diagnosed cancer patients are not routinely tested for HIV or are unaware of their HIV result.

Our analysis has some limitations. In the first 2 years (November 2004 - November 2006) of introduction of the HIV section of the questionnaire, it was only used for patients aged 55 or less; thereafter it was used for all patients. Patients not interviewed on HIV testing were therefore older, and had a lower HIV prevalence than those interviewed (see Additional file 1: Table S5). This might have inflated overall HIV prevalence in the study. Furthermore, there was potential for recall bias and differential reporting of previous HIV testing in patients who had and had not previously tested positive for HIV. Although interviews were conducted by experienced nurse counsellors there was possible social desirability bias, as patients might want to give health care workers responses which cast them favourably. Self-reported HIV status may overestimate true lack of awareness of HIV status where patients who are aware of their HIV positive status may report unknown or HIV negative status [34]. Hence HIV stigma might have affected the high prevalence of undiagnosed HIV. The study was limited to black cancer patients who were mainly from southern Gauteng province; thus the results may not apply to other provinces in South Africa or other countries in sub-Saharan Africa. This study was conducted during the period 20042009; since then there has been continued ART scale-up, and in 2010, national HIV testing guidelines were published and a national HIV testing campaign was implemented $[6,35]$. Therefore current HIV testing patterns and HIV burden in cancer patients might differ from the findings of this study. HIV testing patterns in cancer patients in South Africa had not previously been studied. The current analysis provides a baseline picture of HIV testing patterns in cancer patients in the first five years of the roll-out of antiretroviral combination therapy in South Africa. Another strength is the large sample size, which allowed for precise estimates. The majority of patients had independent study related HIV test results and most other variables were fairly complete.

\section{Conclusions}

HIV prevalence is higher in black cancer patients in Johannesburg than in the general black population, even among patients with cancers which are not AIDS defining. Clinicians should not miss the opportunity to offer PITC to cancer patients at the time of cancer diagnosis. The HIV testing patterns in black cancer patients reflect targeted HIV testing in the reproductive age group. More than a third of newly diagnosed black cancer patients with HIV were unaware of their HIV status. This emphasises the need for implementation of PITC not only in the general population, but also in black cancer patients in South Africa's high HIV prevalence setting. Routine opt-out HIV testing in black cancer patients should be implemented as standard of care in South Africa.

\section{Additional file}

Additional file 1: Table S5. Differences in characteristics of patients interviewed and not interviewed on HIV testing. Table S6. prevalence of HIV and undiagnosed HIV by cancer type.

\section{Abbreviations}

AIDS: Acquired immunodeficiency syndrome; ELISA: Enzyme linked immunosorbent assay; HIV: Human immunodeficiency virus; IARC: International Agency for Research on Cancer; ICD-O-3: International Classification of Diseases for Oncology, Third Edition; JCCCS: Johannesburg 
Cancer Case-control Study; KS: Kaposi sarcoma; NHL: Non-Hodgkin lymphoma; PITC: Provider-initiated HIV testing and counselling; PMTCT: Prevention of mother-to-child transmission of HIV.

\section{Competing interests}

The authors declare that they have no known competing interests.

\section{Authors' contributions}

MIU conceived the study and contributed to the writing of the manuscript. MS wrote the first draft of the manuscript and performed the statistical analysis. CB and ME contributed to the writing of the manuscript. All authors read and approved the final manuscript.

\section{Acknowledgements}

The authors wish to acknowledge Sisters Gloria Mokwatle, Patricia Rapoho and Pheladi Kale who carried out the interviews and collected blood specimens from the patients included in this analysis, Mrs Lettie Bester who prepared the specimens for testing and storage, and Mr Tonicah Maphanga for maintaining the JCCCS database. We thank the oncology clinicians and the administration at Charlotte Maxeke Johannesburg Academic Hospital (formerly Johannesburg General Hospital) for assistance and for access to patients in their care; we thank the patients who gave freely of their time. We thank Dr Khangelani Zuma from Human Sciences Research Council for providing 5 year age-specific HIV prevalence in black men and women for 2008 in South Africa.

Data from this study were presented at the $20^{\text {th }}$ Conference on Retroviruses and Opportunistic Infections in Atlanta, March 2013.

\section{Funding}

The Cancer Epidemiology Research Group at the National Health Laboratory Service was funded by the South African Medical Research Council and the (South African) National Health Laboratory Service. Mazvita Sengayi's PhD is funded by The International Epidemiological Databases to Evaluate AIDS in Southern Africa (leDEA SA), Grant Number U01Al069924 from the NIH (NIAD, NICHD, NCI) (PI: Egger and Davies). Funders had no role in study design, data collection and analysis, decision to publish, or preparation of the manuscript.

\section{Author details}

${ }^{1}$ NHLS/MRC Cancer Epidemiology Research Group, National Cancer Registry, National Health Laboratory Service, Johannesburg, South Africa. ${ }^{2}$ Graduate School for Cellular and Biomedical Sciences, University of Bern, Bern, Switzerland. ${ }^{3}$ School of Pathology, Faculty of Health Sciences, University of the Witwatersrand, Johannesburg, South Africa. ${ }^{4}$ Institute of Social and Preventive Medicine (ISPM), University of Bern, Bern, Switzerland. ${ }^{5}$ Centre for Infectious Disease Epidemiology and Research (CIDER), School of Public Health and Family Medicine, University of Cape Town, Cape Town, South Africa.

\section{Received: 15 August 2014 Accepted: 6 March 2015}

\section{Published online: 18 March 2015}

\section{References}

1. IARC working group on the evaluation of carcinogenic risks to Humans. IARC monographs on the evaluation of carcinogenic risks to humans: Human Immunodeficiency Viruses and Human T-Cell Lymphotropic Viruses, vol. 67. Lyon: World Health Organization, International Agency for Research on Cancer; 1996. p. 183.

2. Shisana O, Rehle T, Simbayi L, Zuma K, Jooste S, Zungu N, et al. South African national HIV prevalence, incidence and behaviour survey, 2012. Cape Town: Human Sciences Research Council Press; 2014.

3. Sigel K, Dubrow R, Silverberg M, Crothers K, Braithwaite S, Justice A. Cancer screening in patients infected with HIV. Curr HIV/AIDS Rep. 2011;8:142-52.

4. Chiao EY, Dezube BJ, Krown SE, Wachsman W, Brock MV, Giordano TP, et al. Time for oncologists to opt in for routine opt-out HIV testing? JAMA. 2010;304:334-9.

5. Cave J, Edwards SG, Miller RF, Ardeshna KM, Lee SM. Should we implement "opt-out" HIV testing for patients with lymphoma? Clin Med. 2009;9:320-2.

6. National Department of Health. National HIV counselling and testing policy guidelines. Pretoria: National Department of Health; 2010. p. 24.
7. World Health Organization. Guidance on provider-initiated HIV testing and counselling in health facilities. Geneva: World Health Organization; 2007.

8. Dalal S, Lee C, Farirai T, Schilsky A, Goldman T, Moore J, et al. Provider-initiated HIV testing and counseling: increased uptake in two public community health centers in South Africa and implications for scale-up. PLoS One. 2011;6:e27293.

9. Hensen B, Baggaley R, Wong VJ, Grabbe KL, Shaffer N, Lo Y-RJ, et al. Universal voluntary HIV testing in antenatal care settings: a review of the contribution of provider-initiated testing \& counselling. Trop Med Int Health. 2012;17:59-70.

10. Peltzer K, Matseke G, Mzolo T, Majaja M. Determinants of knowledge of HIV status in South Africa: results from a population-based HIV survey. BMC Public Health. 2009;9:174.

11. Snow RC, Madalane M, Poulsen M. Are men testing? Sex differentials in HIV testing in Mpumalanga Province, South Africa. AIDS Care. 2010;22:1060-5.

12. Pitpitan EV, Kalichman SC, Eaton LA, Cain D, Sikkema KJ, Skinner D, et al. AIDS-related stigma, HIV testing, and transmission risk among patrons of informal drinking places in Cape Town, South Africa. Ann Behav Med. 2012:43:362-71.

13. Kranzer K, van Schaik N, Karmue U, Middelkoop K, Sebastian E, Lawn SD, et al. High prevalence of self-reported undiagnosed HIV despite high coverage of HIV testing: a cross-sectional population based sero-survey in South Africa. PLoS One. 2011;6:e25244.

14. Venkatesh KK, Madiba P, De Bruyn G, Lurie MN, Coates TJ, Gray GE. Who gets tested for HIV in a South African urban township? Implications for test and treat and gender-based prevention interventions. J Acquir Immune Defic Syndr. 2011;56:151-65.

15. Tabana H, Doherty T, Swanevelder S, Lombard C, Jackson D, Zembe W, et al. Knowledge of HIV status prior to a community HIV counseling and testing intervention in a rural district of South Africa: results of a community based survey. BMC Infect Dis. 2012;12:73.

16. Stein L, Urban Ml, O'Connell D, Yu XQ, Beral V, Newton R, et al. The spectrum of human immunodeficiency virus-associated cancers in a South African black population: results from a case-control study, 1995-2004. Int J Cancer. 2008;122:2260-5.

17. Fritz A, Percy C, Jack A, Shanmugaratnam K, Sobin L, Parkin DM, et al. International Classification of Diseases for Oncology. Third ed. Geneva: World Health Organization; 2000.

18. Centers for Disease Control and Prevention. 1993 revised classification system for HIV infection and expanded surveillance case definition for AIDS among adolescents and adults. MMWR Recomm Rep. 1992;41:1-19.

19. Shisana O, Rehle T, Simbayi L, Zuma K, Jooste S, Pillay-van Wyk V, et al. South African national HIV prevalence, incidence, behaviour and communication survey, 2008: A turning tide among teenagers? Cape Town: Human Sciences Research Council Press; 2009.

20. Fact Sheets - Alcohol use and health [http://www.cdc.gov/alcohol/factsheets/alcohol-use.htm].

21. Pacella-Norman R, Urban Ml, Sitas F, Carrara H, Sur R, Hale M, et al. Risk factors for oesophageal, lung, oral and laryngeal cancers in black South Africans. Br J Cancer. 2002;86:1751-6.

22. National Department of Health. National Antenatal Sentinel HIV and Syphilis Prevalence Survey in South Africa, 2009. Pretoria: National Department of Health; 2010. p. 1-72.

23. National Department of Health. The 2012 national antenatal sentinel HIV and herpes simplex type-2 prevalence survey, South Africa. Pretoria: National Department of Health; 2013.

24. Cremin I, Cauchemez S, Garnett GP, Gregson S. Patterns of uptake of HIV testing in sub-Saharan Africa in the pre-treatment era. Trop Med Int Heal. 2012;17:e26-37.

25. Goga A, Dinh T, Jackson D. Evaluation of the effectiveness of the national prevention of mother-to-child transmission (PMTCT) programme on infant HIV measured at six weeks postpartum in South Africa, 2010. Cape Town: South African Medical Research Council, National Department of Health of South Africa and PEPFAR/US Centers for Disease Control and Prevention; 2012.

26. Van Bogaert L-JJ. Age at diagnosis of preinvasive and invasive cervical neoplasia in South Africa: HIV-positive versus HIV-negative women. Int J Gynecol Cancer. 2011;21:363-6.

27. Mbulaiteye SM, Katabira ET, Wabinga H, Parkin DM, Virgo P, Ochai R, et al. Spectrum of cancers among HIV-infected persons in Africa: the Uganda AIDS-Cancer Registry Match Study. Int J Cancer. 2006;118:985-90. 
28. Majeed U, Sekowski A, Ooko F. Vulvar cancer in HIV-positive young women-a treatment challenge: case report. S Afr J Obstet Gynaecol. 2006;12:156-62.

29. Gichuhi S, Sagoo MS, Weiss H a, Burton MJ. Epidemiology of ocular surface squamous neoplasia in Africa. Trop Med Int Health. 2013;18:1424-43.

30. Nagaiah G, Stotler C, Orem J, Mwanda WO, Remick SC. Ocular surface squamous neoplasia in patients with HIV infection in sub-Saharan Africa. Curr Opin Oncol. 2010;22:437-42.

31. Deeken JF, Tjen-A-Looi A, Rudek M a, Okuliar C, Young M, Little RF, et al. The rising challenge of non-AIDS-defining cancers in HIV-infected patients. Clin Infect Dis. 2012;55:1228-35.

32. Fraser-Hurt N, Zuma K, Njuho P, Chikwava F, Slaymaker E, Hosegood V, et al. The HIV epidemic in South Africa: what do we know and how has it changed? Pretoria: South African National AIDS Council; 2011. p. 74.

33. Pola EC, Masanganise R, Rusakaniko $S$. The trend of ocular surface squamous neoplasia among ocular surface tumour biopsies submitted for histology from Sekuru Kaguvi Eye Unit, Harare between 1996 and 2000. Cent Afr J Med. 2003;49:1-4.

34. Sanchez TH, Kelley CF, Rosenberg E, Luisi N, O'Hara B, Lambert R, et al. Lack of awareness of Human Immunodeficiency Virus (HIV) Infection: problems and solutions with self-reported HIV serostatus of men who have sex with men. Open Forum Infect Dis. 2014;1:ofu084-4.

35. South African National AIDS Council. The National HIV Counselling and Testing Campaign Strategy. Pretoria: South African National AIDS Council; 2010. February.

\section{Submit your next manuscript to BioMed Central and take full advantage of:}

- Convenient online submission

- Thorough peer review

- No space constraints or color figure charges

- Immediate publication on acceptance

- Inclusion in PubMed, CAS, Scopus and Google Scholar

- Research which is freely available for redistribution 